\title{
BMJ Open Patient satisfaction in China: a national survey of inpatients and outpatients
}

\author{
Huigang Liang (D) ,' Yajiong Xue, ${ }^{2}$ Zhi-ruo Zhang ${ }^{3}$
}

To cite: Liang $\mathrm{H}$, Xue Y, Zhang Z. Patient satisfaction in China: a national survey of inpatients and outpatients. BMJ Open 2021;11:e049570. doi:10.1136/ bmjopen-2021-049570

- Prepublication history and additional supplemental material for this paper are available online. To view these files, please visit the journal online (http://dx.doi.org/10.1136/ bmjopen-2021-049570).

Received 30 January 2021 Accepted 24 August 2021

Check for updates

(c) Author(s) (or their employer(s)) 2021. Re-use permitted under CC BY-NC. No commercial re-use. See rights and permissions. Published by BMJ.

${ }^{1}$ Business and Information Technology, The University of Memphis, Memphis, Tennessee, USA

${ }^{2}$ Management Information Systems, East Carolina University, Greenville, North Carolina, USA

${ }^{3}$ Community Health \& Behavioral Medicine, Shanghai Jiao Tong University, Shanghai, Shanghai, China

Correspondence to

Dr Yajiong Xue;

xuey@ecu.edu and

Dr Zhi-ruo Zhang;

zhangzhiruo@sjtu.edu.cn

\section{ABSTRACT}

Objectives Patient satisfaction is an important indicator of hospital healthcare quality. Little up-to-date information of patient satisfaction in China is available. This study attempts to gain a holistic understanding of patient satisfaction in China and identify the key antecedents of patient satisfaction.

Design A cross-sectional national survey was conducted in 2018.

Setting Hospitals in 27 provinces and 4 municipalities in 4 regions of China.

Participants A random sample of 15699 patients who visited 1304 hospitals were surveyed, with around 500 from each of the 27 provinces and 4 municipalities.

Primary and secondary outcome measures The Hospital Consumer Assessment of Healthcare Providers and Systems questionnaire was used to measure patients' overall satisfaction and willingness to recommend the hospital.

Results We found significant variation in overall patient satisfaction but little variation in hospital recommendation across the four broad regions. Moreover, we examined determinants of patient satisfaction and their likelihood to recommend the hospital. The overall satisfaction for inpatients and outpatients is commonly influenced by communication with doctors (inpatient: $\beta=0.524, p<0.001$ outpatient: $\beta=0.541, p<0.001$ ), hospital cleanness (inpatient: $\beta=0.165, p<0.05$; outpatient: $\beta=0.144$, $p<0.001$ ) and acceptable charges (inpatient: $\beta=1.481$, $p<0.001$; outpatient: $\beta=1.045, p<0.001)$. Both inpatients and outpatients are more likely to recommend the hospital if there are communication with doctors (inpatient: $\mathrm{OR}=1.743, \mathrm{p}<0.001$; outpatient: $\mathrm{OR}=1.647, \mathrm{p}<0.001$ ), acceptable charges (inpatient: $0 R=2.660, p<0.001$; outpatient: $\mathrm{OR}=2.433, \mathrm{p}<0.001$ ). Outpatient satisfaction and hospital recommendation are also influenced by time spent with doctors (satisfaction: $\beta=0.301$, $\mathrm{p}<0.001$; recommend: $\mathrm{OR}=1.430, \mathrm{p}<0.001$ ) and waiting time (satisfaction: $\beta=-0.318, p<0.001$; recommend: $\mathrm{OR}=0.844, \mathrm{p}<0.001$ ).

Conclusions There are regional differences of patient satisfaction in China. Patient satisfaction is influenced by a variety of hospital factors and province/municipality factors. The influencing factors of patient satisfaction may not motivate patients to recommend the hospital.

\section{INTRODUCTION}

Patient satisfaction has received tremendous attention from healthcare providers, researchers and policy makers as an indispensable component of high-quality healthcare
Strengths and limitations of this study

This study conducts a large-scale national survey of patient satisfaction in China.

- The respondents are randomly selected from 27 provinces and 4 municipalities.

- It examines both inpatients' and outpatients' satisfaction.

- The sample of this study is limited to patients with mobile phones.

- The cross-sectional design cannot lead to causal conclusions between influencing factors and patient satisfaction.

systems. ${ }^{1}$ Recent research shows that patient satisfaction is associated with higher care quality and efficiency such as improved treatment compliance, lower readmission and mortality and shorter length of stay. ${ }^{2}$ Despite ongoing debates regarding whether patient satisfaction can lead to better clinical outcomes, ${ }^{34}$ it has been widely accepted and institutionalised as an important care quality indicator for hospitals in many countries. ${ }^{5}$ For example, in the USA, ${ }^{6}$ where hospitals are mandated by the Centers for Medicare and Medicaid Services (www.cms.gov) to report patient satisfaction scores and underperforming hospitals on the patient satisfaction metric will be penalised. The patient satisfaction ratings of American hospitals are published online for consumers to compare hospitals when seeking care, which reduces information asymmetry between patients and healthcare providers and helps patients make informed decisions. In addition, hospitals can use patient-specific satisfaction metric to identify areas for improvement, thus increasing patient experience with physicians and nurses and hopefully improving their clinical outcomes. $^{78}$

The physician-patient relationship in China used to be paternalistic and characterised by salient power imbalance, where patients follow treatment advice from physicians and play a passive role in the care process. The recent years have witnessed 
an increasing advocation of patient-centred care in the Chinese healthcare system. Healthcare providers and policy makers in China realised the importance of patient satisfaction and started to treat it as an indicator of care quality. ${ }^{9}$ For example, the Chinese government launched a national healthcare improvement initiative in 2015 with explicit goals to enhance patient experience and satisfaction..$^{10}$ Moreover, violence against doctors from angry patients has long been a serious problem in China. ${ }^{11} 12$ Tragedies continued taking place throughout the past decade, leading to serious physician injuries and fatalities. ${ }^{13}$ Increasing patient satisfaction is key to ameliorate the tension between patients and physicians.

Several studies have examined patient satisfaction and its determinants in China's inpatient and outpatient settings. ${ }^{14-17}$ However, prior studies are either limited by geographical regions or focused on outpatient satisfaction only. Two studies investigated both outpatient and inpatient satisfaction based on a national survey, but the data were almost 10 years and 5 years old, respectively. ${ }^{1617}$ China has gone through tremendous changes in economic development and healthcare reform in the past 10 years, which will influence patient satisfaction. In addition, the past studies did not use standardised instruments to measure patient satisfaction, making the findings non-comparable between studies or across countries. Therefore, the objective of this study is to gain a holistic understanding of patient satisfaction across regions at the national level and how patient satisfaction is influenced by characteristics of the patient, the hospital and the region in China. We investigate both inpatient satisfaction and outpatient satisfaction, because in China, almost all outpatient visits are conducted in hospitals. Therefore, a hospital's healthcare quality is reflected by both inpatient satisfaction, and also outpatient satisfaction.

\section{METHOD}

\section{Study design, setting and participants}

We conducted a cross-sectional national survey in China in September 2018. The data collection lasted 19 days (1 September 2018 to 19 September 2018). The participants were from 4 municipalities and 27 provinces, a total of 31 sites. The China Telecommunications Corporation provided us a list of mobile phone numbers at each of the 31 sites of this study. For each site, we randomly selected phone numbers to call the potential participants to take the survey. The computer-assisted telephone interviewing (CATI) was employed to call potential participants to collect data based on the questionnaire. A total of 16831 calls were answered by respondents, and 11959 of them agreed to participate and completed the survey, showing a response rate of $71 \%$. The number of completed surveys was counted for each site until it reached or exceeded 500 . We planned to collect 500 responses from each site. The target sample size of 500 was determined by a power analysis which intends to provide $85 \%$ power at the 0.05 significance level for regression analysis assuming small effect sizes of the predictors $(\mathrm{f}=0.05) .{ }^{18}$ Since the number of responses was checked at the end of each day, it is possible to have a little more than 500 responses from a specific site. The CATI required answer to each question; hence, there were no missing values in the collected data. Each respondent participated either as an inpatient or outpatient, not both. Their role was determined by the their most recent hospital visit: to see a doctor or to be hospitalised. Since hospitals in China are predominantly public, we restricted our study scope to patient visits in public hospitals. To reduce memory bias, the hospital visit must be within a year. Respondents who were younger than 18 or did not visited a hospital in the past year were excluded from this study. Verbal consent was obtained before data collection. Each survey took about 5-10 min to complete. The participants received no monetary reward for their participation.

\section{Patient and public involvement}

The questionnaire design involved patients. After the questionnaire was drafted, it was pretested with 10 patients (5 inpatients and 5 outpatients) in a hospital in Shanghai. Feedback from the patients was used to improve the understandability of the questions. The conduct of this study involved a representative national sample of patients. We reached out to a large number of patients from each province or municipality in China to understand their satisfaction with medical services they received. We plan to widely disseminate the findings of this study to the public by sharing information on popular press and social media.

\section{Instruments}

A questionnaire was created to measure patient satisfaction based on the Hospital Consumer Assessment of Healthcare Providers and Systems (HCAHPS).$^{19}$ We adapted questions from the official Chinese version of the HCAHPS survey on its website (https://www.hcahpsonline.org/en/survey-instruments/). The participants were asked to recall their immediate past hospital stay or hospital outpatient visit and answer questions based on that specific experience. Specifically, the inpatient satisfaction questions included 11 items: physician communication (three items, Cronbach's alpha $=0.90$ ), nurse communication (three items, Cronbach's alpha=0.96), quietness (one item), cleanness (one item), medical charges (one item), overall satisfaction (one item) and willingness to recommend (one item); and the outpatient satisfaction questions included eight items: physician communication (three items, Cronbach's alpha=0.93), cleanness (one item), medical charges (one item), waiting time (one item) and time spent with doctors (one item), overall satisfaction (one item) and willingness to recommend (one item). Online supplemental appendix A shows all the questions for measuring inpatient and outpatient satisfaction. During data collection, each participant was asked to report the type of their most recent hospital visit: hospitalisation or outpatient visit. A 
branching logic was built into the CATI chatbot based on the answer to this question, so that the inpatient satisfaction questions were asked for those who had a recent hospitalisation, and the outpatient satisfaction questions were asked for those who had an outpatient visit.

All the questions measuring patient satisfaction were adapted from the official HCAHPS survey, ${ }^{19}$ except three items: medical charges, waiting time and time spent with doctors. These three items were added because expensive medical bills, long waiting time and short time to see the doctor are typical problems in Chinese hospitals. We did not conduct a pilot test of the survey, because our survey is mostly the same as the HCAHPS survey except three questions and the validity of the HCAHPS survey is a standardised instrument that has been rigorously validated. ${ }^{20}$ Patient demographic questions included age, gender, education, marriage status, residence location, annual income and medical insurance.

Additionally, for each hospital to which the patients visited, we manually collected objective data of the hospital characteristics by visiting the official hospital website. These data included hospital level, type, number of beds, number of outpatient visits, number of surgeries, number of hospital stays and number of employees. We also collected regional economic and health status data from the National Bureau of Statistics of China (data.stats. gov.cn), including population, gross domestic product (GDP), GDP per capita, birth rate, death rate, medical insurance coverage rate, number of physicians, number of nurses and patient to physician ratio.

\section{Statistical analysis}

We used Stata for data analysis. Three types of analysis were performed: descriptive analysis, comparative analysis and regression analysis. First, we carried out descriptive analysis to understand the data. We inspected the distribution of data on patient demographics. We also explored the structure of the data to decide what type of analysis was appropriate. Because the patients were nested within the 1304 hospitals where they received care, our data are multilevel in nature. We calculated intraclass correlations (ICCs) and design effects (DE) to determine whether multilevel analysis is necessary. The threshold of 0.05 for ICCs was used to justify the use $(>0.05)$ or non-use $(<0.05)$ of multilevel data analysis. ${ }^{21}$ ICCs are sensitive to imbalanced cluster data with few groups containing many individuals while many groups consist of few individuals. In our data, the patients were concentrated in large hospitals and most of the small hospitals were associated with fewer than 10 patients. Thus, we also computed the $\mathrm{DE}$ by taking into account the group sample size $(\mathrm{DE}=1$ + [Average within group sample size - 1] $\times$ ICC).$^{22}$ If the $\mathrm{DE}$ is no less than 2.0, multilevel analysis is required to address the multilevel nature of the data. We found that the ICCs of all patient satisfaction indicators for either inpatients or outpatients are below 0.05 and the DEs are below 2.0, suggesting that the multilevel structure of our data is unlikely to bias the individual responses.
Therefore, multilevel modelling is not necessary in the subsequent data analysis.

Second, we conducted comparative analysis to examine regional differences of patient satisfaction. A high-level regional comparison is helpful to gain a holistic view of patient satisfaction at the national level. We separately analysed inpatient satisfaction and outpatient satisfaction. We compared the two global patient satisfaction indicators (overall satisfaction and recommend the hospital) for both inpatients and outpatients across four broad regions in China. The National Bureau of Statistics of China categorised the provinces and municipalities into four socioeconomically distinct regions: (1) Eastern region (Beijing, Tianjin, Hebei, Shanghai, Jiangsu, Zhejiang, Fujian, Shandong, Guangdong and Hainan), (2) Central region (Shanxi, Anhui, Jiangxi, Henan, Hubei and Hunan), (3) Western region (Neimenggu, Guangxi, Chongqing, Sichuan, Guizhou, Yunnan, Xizang, Shaanxi, Gansu, Qinghai, Ningxia and Xinjiang) and (4) Northeastern region (Liaoning, Jilin and Heilongjiang). We evaluated how patient satisfaction differ across these four regions by using analysis of variance (ANOVA). Post-hoc pairwise comparison was made by using the Tukey method.

Third, we conducted regression analysis to identify significant determinants of patient satisfaction. Specifically, we examined how the two global satisfaction items, overall satisfaction (10-point scale where 10 means 'completely satisfied' and 0 means 'not satisfied at all') and hospital recommendation ( $1=$ not at all, $2=$ probably not, $3=$ probablyyes, 4=definitelyyes), were influenced by individual demographics, hospital attributes and regional factors (GDP per capita, medical insurance coverage, patient to doctor ratio and amount of level 3 hospitals in a given province or municipality). As the overall satisfaction score is a continuous variable, we applied ordinary least square (OLS) linear regression to regress it on the independent variables. In contrast, hospital recommendation is a categorical variable, we conducted binary logistic regression to regress the logit of the probability that the patient will recommend the hospital on the independent variables. The four possible values of hospital recommendation were consolidated into two $(0=$ not recommend, $1=$ recommend) to fit with binary logistic regression and easy interpretation. Two hospital factors, total beds and patient volume, have missing values, and mean imputation was used to replace the missing values.

\section{RESULTS}

\section{Descriptive analysis: characteristics of respondents}

We collected survey data from 15699 patients, including 3740 inpatients and 11959 outpatients. They are from 27 provinces and 4 municipalities, with about 500 per province/municipality. The respondents reported their recent experience with 1304 different hospitals. Table 1 shows their demographic information for both the inpatient and outpatient samples. 
Open access

Table 1 Patient demographics

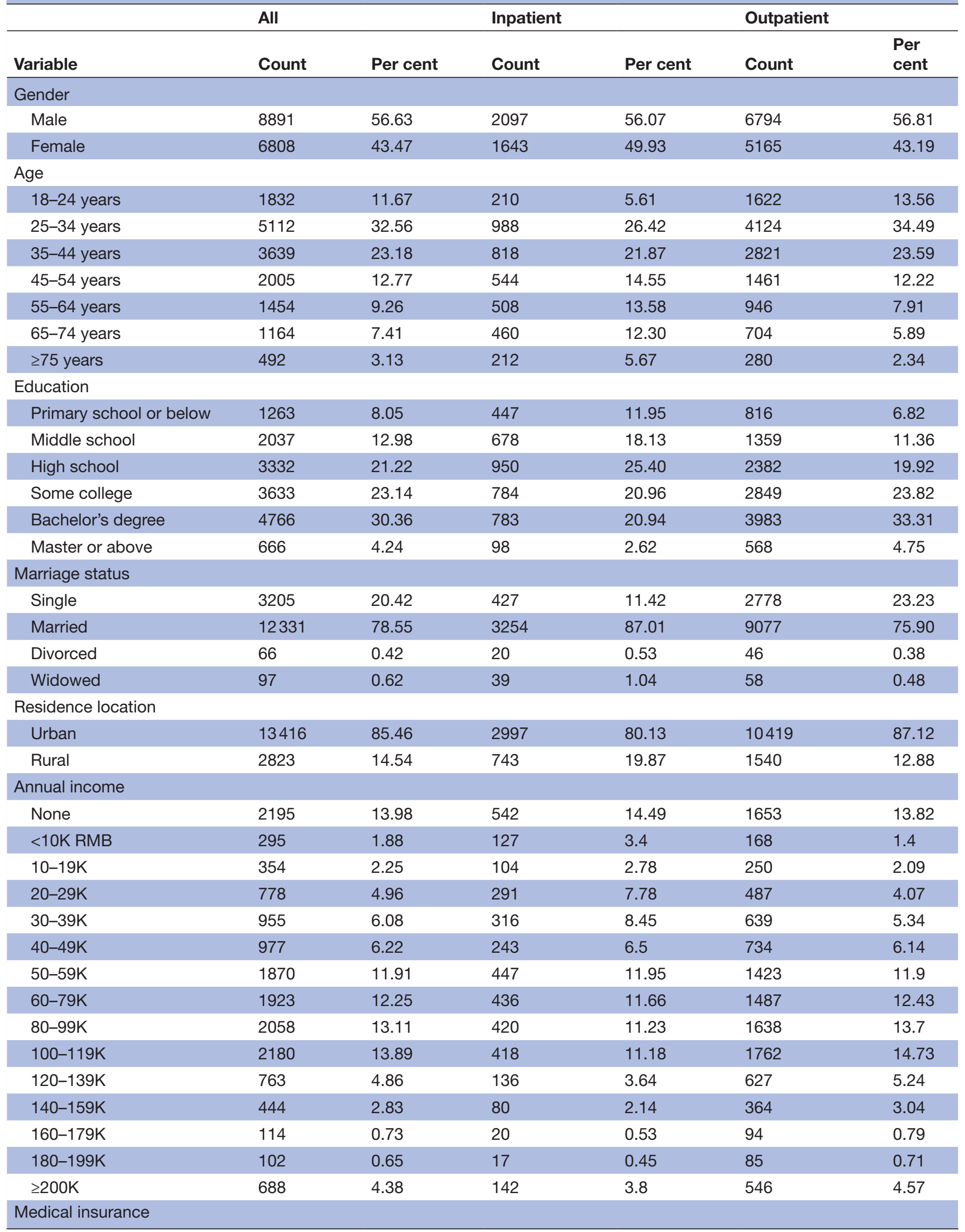


Table 1 Continued

\begin{tabular}{cllllll}
\hline & All & & Inpatient & & \multicolumn{2}{c}{ Outpatient } \\
\hline Variable & Count & Per cent & Count & Per cent & Count & Per \\
cent & 787 & 5.01 & 167 & 4.47 & 620 & 5.18 \\
Not Insured & 14912 & 94.99 & 3573 & 95.53 & 11339 \\
\hline
\end{tabular}

\section{Comparative analysis: differences across broad regions}

The four regions' descriptive statistics of overall satisfaction and hospital recommendation are presented in table 2. The ANOVA tests (see table 3) indicate that there are significant differences among the four broad regions for both inpatient and outpatient overall satisfaction and inpatient hospital recommendation, while there is no regional difference for outpatient hospital recommendation. The post-hoc pairwise comparisons reveal that for overall patient satisfaction, the Northeastern region's is significantly lower than the other three regions, while the other three regions are not significantly different. For outpatient overall satisfaction, the Northeastern regions still has significantly lower scores than the other three regions. In addition, the Eastern region's score is also higher than the Central region. For inpatient hospital recommendation, only the Eastern region is significantly higher than the Northeastern region, and there are no statistically significant differences between any other two regions. Regarding outpatient hospital recommendation, there are no differences between any two regions, confirming the overall ANOVA result.

\section{Regression analysis: determinants of patient satisfaction}

Finally, we conducted OLS linear regression to examine what factors influence patients' satisfaction and binary logistic regression to examine patients' likelihood to recommend the hospital. A single score of communication with doctors was obtained by averaging its three items. A single score of communication with nurses was obtained in the same way. Table 4 shows all the regression results. First, for overall inpatient satisfaction, it is significantly related to communication with doctors $(\beta=0.59$, $\mathrm{p}<0.001)$, hospital cleanness $(\beta=0.16, \mathrm{p}<0.01)$, acceptable charges $(\beta=1.49, p<0.001)$, patients' social class $(\beta=0.08$, $\mathrm{p}<0.001)$, being female $(\beta=0.22, \mathrm{p}<0.001)$, provincial medical insurance coverage rate $(\beta=0.83, \mathrm{p}<0.05)$ and the amount of level 3 hospitals within the province $(\beta=0.01$, $\mathrm{p}<0.05)$.

In contrast, the overall outpatient satisfaction is significantly influenced by communication with doctors $(\beta=0.51, p<0.001)$, time spent with doctors $(\beta=0.35$, $p<0.001)$, waiting time before seeing the doctor $(\beta=-0.31$, $\mathrm{p}<0.001)$, hospital cleanness $(\beta=0.16, \mathrm{p}<0.001)$, acceptable charges $(\beta=1.03, p<0.001)$, patients' health status $(\beta=0.03, p<0.05)$, patients' social class $(\beta=0.08, p<0.001)$, being female $(\beta=0.07, p<0.05)$, age $(\beta=0.04, p<0.01)$, education $(\beta=0.04, p<0.01)$, having medical insurance $(\beta=0.17, p<0.05)$, provincial medical insurance coverage rate $(\beta=0.84, p<0.001)$ and provincial patient to doctor ratio $(\beta=-0.01, p<0.05)$. Moreover, compared with level 1 hospitals, outpatients are more satisfied with level 3 hospitals $(\beta=0.18, \mathrm{p}<0.001)$.

Regarding the likelihood to recommend the hospital to others, inpatients and outpatients are influenced by different sets of factors. For inpatients, the likelihood to recommend the hospital is significantly related to communication with doctors $(\mathrm{OR}=1.65, \mathrm{p}<0.001)$, acceptable charges $(\mathrm{OR}=2.66, \mathrm{p}<0.001)$, social class $(\mathrm{OR}=1.06$, $\mathrm{p}<0.05)$ and being female $(\mathrm{OR}=1.38, \mathrm{p}<0.001)$. Compared with level 1 hospitals, inpatients are more likely to recommend level 3 hospitals to others $(\mathrm{OR}=1.46, \mathrm{p}<0.01)$.

For outpatients, the decision to recommend the hospital is influenced by communication with doctors $(\mathrm{OR}=1.58$, $\mathrm{p}<0.001)$, time spent with doctors $(\mathrm{OR}=1.44, \mathrm{p}<0.001)$, waiting time before seeing the doctor $(\mathrm{OR}=0.84, \mathrm{p}<0.001)$, acceptable charges $(\mathrm{OR}=2.32, \mathrm{p}<0.001)$, patients' social class $(\mathrm{OR}=1.06, \quad \mathrm{p}<0.001)$, being female $(\mathrm{OR}=1.14$, $\mathrm{p}<0.01)$, having medical insurance $(\mathrm{OR}=1.298, \mathrm{p}<0.05)$,

\begin{tabular}{|c|c|c|c|c|c|c|c|c|c|c|}
\hline \multirow[t]{3}{*}{ Region } & \multicolumn{5}{|c|}{ Inpatient } & \multicolumn{5}{|c|}{ Outpatient } \\
\hline & \multirow[b]{2}{*}{ Count } & \multicolumn{2}{|c|}{$\begin{array}{l}\text { Overall } \\
\text { satisfaction }\end{array}$} & \multicolumn{2}{|c|}{$\begin{array}{l}\text { Recommend the } \\
\text { hospital }\end{array}$} & \multirow[b]{2}{*}{ Count } & \multicolumn{2}{|c|}{$\begin{array}{l}\text { Overall } \\
\text { satisfaction }\end{array}$} & \multicolumn{2}{|c|}{$\begin{array}{l}\text { Recommend the } \\
\text { hospital }\end{array}$} \\
\hline & & Mean & SD & Mean & SD & & Mean & SD & Mean & SD \\
\hline Eastern & 867 & 7.81 & 2.03 & 3.02 & 0.88 & 4158 & 7.59 & 1.80 & 2.99 & 0.86 \\
\hline Central & 746 & 7.66 & 2.02 & 3.00 & 0.91 & 2328 & 7.42 & 1.85 & 3.00 & 0.88 \\
\hline Western & 1705 & 7.61 & 2.06 & 2.96 & 0.81 & 4318 & 7.49 & 1.88 & 2.98 & 0.75 \\
\hline Northeastern & 422 & 7.15 & 2.60 & 2.87 & 1.01 & 1155 & 7.22 & 2.29 & 3.05 & 0.92 \\
\hline Overall & 3740 & 7.61 & 2.12 & 2.97 & 0.87 & 11959 & 7.49 & 1.89 & 2.99 & 0.83 \\
\hline
\end{tabular}


Table 3 Regional comparison of overall patient satisfaction and likelihood to recommend the hospital

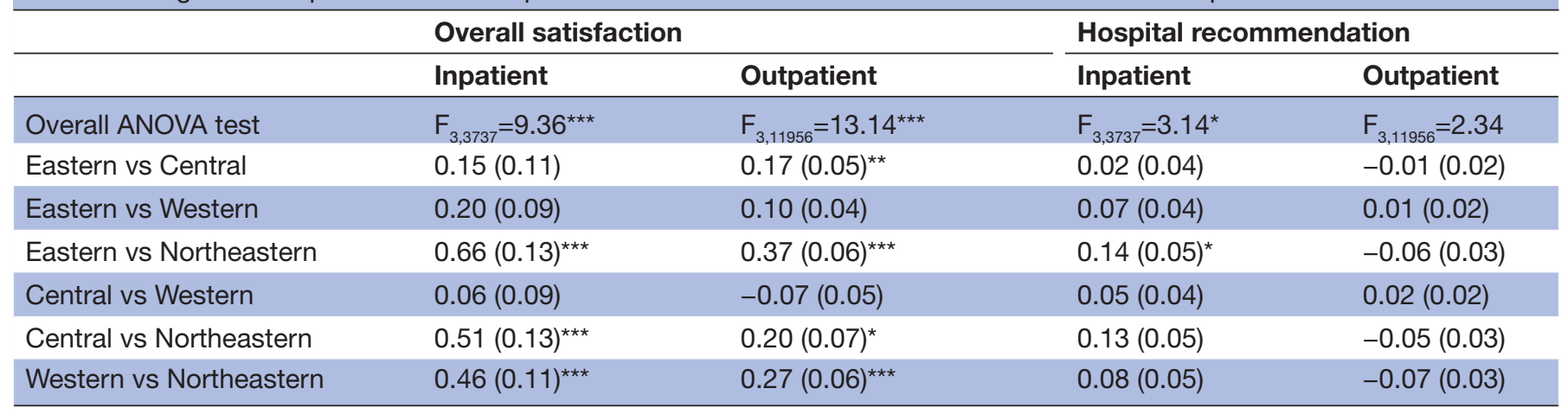

Note: ${ }^{*} \mathrm{p}<0.05,{ }^{* *} \mathrm{p}<0.01,{ }^{* * \star} \mathrm{p}<0.001$, two-tailed significance test. Pairwise comparisons are based on Tukey tests. Numbers in parentheses are SEs.

ANOVA, analysis of variance.

hospital beds $(\mathrm{OR}=1.40, \mathrm{p}<0.01)$ and provincial medical insurance coverage rate $(\mathrm{OR}=2.36, \mathrm{p}<0.01)$.

\section{DISCUSSION}

This study offers important and interesting insights about patient satisfaction in China and possibly other countries. A previous study, the 2015 China National Patient Survey which also covered patients from 27 provinces and 4 municipalities, reported an outpatient satisfaction score of 4.42 and an inpatient satisfaction score of 4.67 (on a 5-point scale) ${ }^{17}$ Converted into a 10-point scale used in this study, that would be 8.84 and 9.34, respectively, which are much higher than what we found (outpatient satisfaction $=7.49$; inpatient satisfaction $=7.61$ ). The previous reported scores might be inflated because the data were collected via face-to-face interviews which could be intrusive and lead to patients' over-reporting. In addition, the use of HCAHPS survey items allows us to compare patient satisfaction between China and other countries such as the USA. ${ }^{23}$ A simple comparison suggests that the inpatient satisfaction ratings between the USA and China are similar. ${ }^{\mathrm{i}}$ However, this can only serve as a rough estimate due to many differences between the USA and Chinese healthcare systems-for example, most American hospitals are private but most Chinese hospitals are public.

This study identifies four factors that universally influence both overall satisfaction and willingness to recommend hospital for both inpatients and outpatients: communication with doctors, medical charges, social class and gender. It suggests that when doctors make effective communication with patients and the hospital's medical charges are reasonable, patients will be more satisfied and more likely to recommend the hospital

\footnotetext{
${ }^{\mathrm{i}}$ We extracted from hcahpsonline.org the summary of HCAHPS survey results for the period between October 2017 and September 2018, the same time that our study was conducted. The summary indicates that American inpatient overall satisfaction was 73 and the recommend-thehospital score was 72. The Chinese inpatient overall satisfaction was 76 (converted from 7.61 on a 10-point scale) and the recommend-thehospital score was 74 (converted from 2.97 on a 4-point scale).
}

to others. Patient-physician communication has long been found to play an important role in patient-centred care and improve patient satisfaction. ${ }^{24}{ }^{25}$ Our research corroborates this long-held belief. On the other hand, high medical cost is always a major concern for patients, and research shows that prices of medical services have a significant impact on patient satisfaction. ${ }^{26}$ A previous study finds that expensive medical charge is a major determinant of patient dissatisfaction ${ }^{12}$ If patients think the medical bills are overly high, they may perceive it as unfair, which lowers their satisfaction with the hospital. Our findings also suggest that patients in higher social classes are more satisfied than those in lower social classes, and female patients are more satisfied than male patients. The impact of social class is probably because patients in upper classes have more material and social resources so that they encounter fewer obstacles when seeking medical help. The gender differentiation in patient satisfaction can be explained by the theory that women hold lower expectations than men. ${ }^{27}$ Hence, even with exactly the same experience in a hospital, female patients would have a higher level of satisfaction than male patients.

Long waiting time and short time to talk with the doctor are prominent problems for outpatient visits in China. In large Chinese hospitals, doctors see many patients per day and have only a few minutes to spend with a patient. ${ }^{2829}$ This makes the outpatient encounter a highly stressful experience for patients. Indeed, this study shows that outpatients are less satisfied if they spend less time with doctors and more time waiting. Our finding is consistent with prior research showing that waiting time and patient-doctor relationship are important influencing factors of patient satisfaction. ${ }^{17}$ If the patient does not have enough time to talk to the doctor, effective patient-physician communication cannot be achieved. Patient-physician communication is widely acknowledged as an essential element of medical care. ${ }^{25}$ Sufficient time is prerequisite for effective communication. However, in countries where medical resources are limited and the patient to doctor ratio is high, it is challenging to reduce waiting time and 


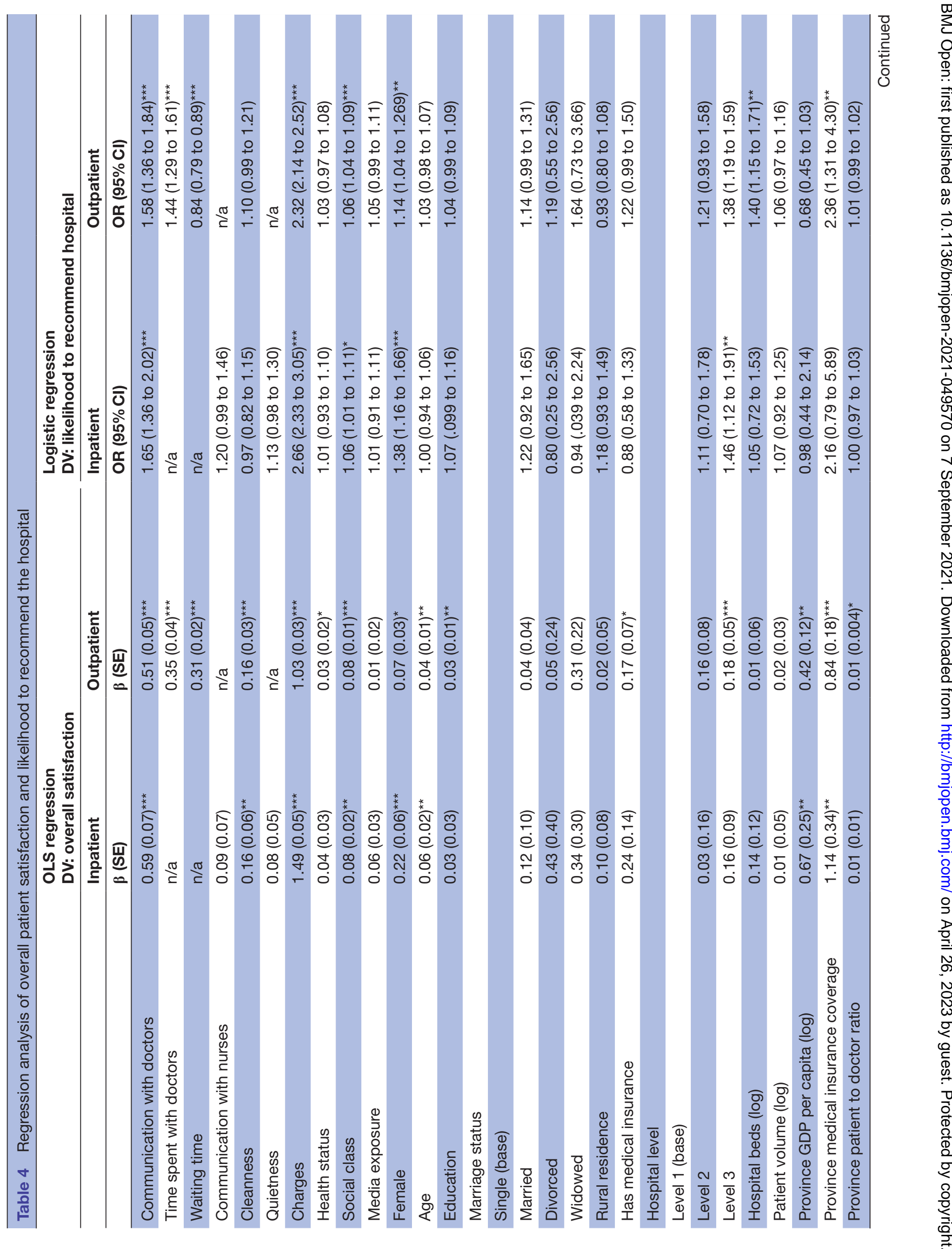




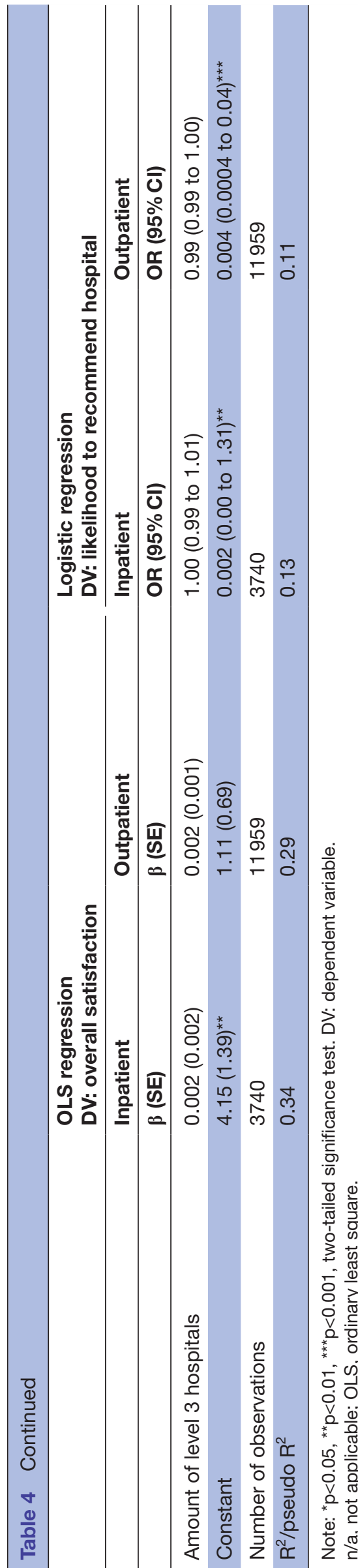

increase patient-physician meeting time. Innovative solutions such as telemedicine and online consultation may help to address this issue.

Our findings suggest that the factors significantly associated with overall satisfaction may not be able to motivate patients to recommend the hospital. For example, hospital cleanness is associated with overall satisfaction but not hospital recommendation for both inpatients and outpatients. A clean environment can be considered a basic requirement which may increase patient satisfaction but may not be impressive enough to trigger an urge within the patients to recommend it to their family and friends. Age and GDP per capita are another two factors that increase patient satisfaction but have no effect on hospital recommendation. Older people may be more understanding, so they can be satisfied with acceptable medical services; but in the meantime, they become more cautious and less risk-taking, ${ }^{30}$ so they may be reluctant to recommend to others a hospital for which they have little expertise to evaluate its quality. GDP per capita reflects the economic development of a province. In high GDP provinces, hospitals receive more funding from the local governments and are likely to have more advanced facilities, equipment and health professionals, which all could increase patient satisfaction. However, it is unclear why these improvements cannot make patients more willing to recommend the hospital and future research is needed to explore further. Moreover, we find that the province's medical insurance coverage rate is positively associated with inpatient satisfaction, outpatient satisfaction and outpatients' likelihood to recommend the hospital. A possible explanation is that when a province has broader medical insurance coverage, it suggests that the local governments have stronger health policy and more medical resources, which increase care accessibility and patient satisfaction.

This study has three limitations. First, since we used CATI to collect data, the respondents must have a cell phone. Those in poverty who have no cell phones were not included, which may inflate our findings of patient satisfaction. However, according to the Pew Research Center, only 3\% people in China have no cell phones. Therefore, our findings are unlikely to be biased by the CATI method. Second, due to privacy concerns, we did not ask patients to report their specific conditions. It is possible that patients with certain conditions have particularly higher or lower satisfaction. Future research is needed to explore how patient satisfaction is related to their medical conditions being treated. Third, we did not survey patients from Macau and Hong Kong. Hence, our findings cannot be generalised to these regions. Despite these limitations, we believe that our findings can be cautiously generalised to most of the Chinese population because of our random sampling from 31 provinces/ municipalities of China. 


\section{CONCLUSIONS}

Based on a national survey of 11959 outpatients and 3740 inpatients in China, this study finds significant variation in overall patient satisfaction but little variation in hospital recommendation across the four broad regions. The Northeastern region has lower patient satisfaction than the other three regions. A variety of influencing factors are identified for inpatients' and outpatients' overall satisfaction and hospital recommendation. Our findings can help hospitals understand how to improve patient satisfaction. However, since most hospitals in China do not have any systematic and reliable way to measure patient satisfaction and thus are unaware how satisfied their patients are, a formal patient satisfaction measurement system is needed to monitor changes of patient satisfaction. The Chinese government also needs to enact policies to make hospitals realise the importance of patient satisfaction and motivate them to take effective actions to improve patient satisfaction.

Contributors $\mathrm{HL}$ : research design, survey design, data analysis and manuscript writing; YX: data analysis and manuscript writing; ZZ: research design and data collection.

Funding The authors have not declared a specific grant for this research from any funding agency in the public, commercial or not-for-profit sectors.

Competing interests None declared.

Patient consent for publication Not required.

Ethics approval This study was approved by the institutional review board of Shanghai Jiaotong University (No. M02710).

Provenance and peer review Not commissioned; externally peer reviewed.

Data availability statement № data are available.

Supplemental material This content has been supplied by the author(s). It has not been vetted by BMJ Publishing Group Limited (BMJ) and may not have been peer-reviewed. Any opinions or recommendations discussed are solely those of the author(s) and are not endorsed by BMJ. BMJ disclaims all liability and responsibility arising from any reliance placed on the content. Where the content includes any translated material, BMJ does not warrant the accuracy and reliability of the translations (including but not limited to local regulations, clinical guidelines, terminology, drug names and drug dosages), and is not responsible for any error and/or omissions arising from translation and adaptation or otherwise.

Open access This is an open access article distributed in accordance with the Creative Commons Attribution Non Commercial (CC BY-NC 4.0) license, which permits others to distribute, remix, adapt, build upon this work non-commercially, and license their derivative works on different terms, provided the original work is properly cited, appropriate credit is given, any changes made indicated, and the use is non-commercial. See: http://creativecommons.org/licenses/by-nc/4.0/.

ORCID iD

Huigang Liang http://orcid.org/0000-0001-6597-4461

\section{REFERENCES}

1 Institute of Medicine. Crossing the quality chasm: a new health system for the 21st century. Washington, DC: National Academies Press, 2001.
2 Tsai TC, Orav EJ, Jha AK. Patient satisfaction and quality of surgical care in US hospitals. Ann Surg 2015;261:2-8.

3 Manary MP, Boulding W, Staelin R, et al. The patient experience and health outcomes. New England Journal of Medicine 2013;368:201-3.

4 Fenton JJ, Jerant AF, Bertakis KD. The cost of satisfaction: a national study of patient satisfaction, health care utilization, expenditures, and mortality. Archives of internal medicine 2012;172:405-11.

5 Rozenblum R, Lisby M, Hockey PM, et al. Uncovering the blind spot of patient satisfaction: an international survey. BMJ Qual Saf 2011;20:959-65.

6 Lyu H, Wick EC, Housman M, et al. Patient satisfaction as a possible indicator of quality surgical care. JAMA Surg 2013;148:362-7.

7 Alasad J, Tabar NA, AbuRuz ME. Patient satisfaction with nursing care: measuring outcomes in an international setting. The Journal of Nursing Administration 2015;45:563-8.

8 Grol R. Improving the quality of medical care: building bridges among professional pride, payer profit, and patient satisfaction. JAMA 2001;286:2578-85.

$9 \mathrm{Hu} \mathrm{L}$, Ding H, Hu G, et al. How perceived quality of care affects outpatient satisfaction in China: a cross-sectional study of 136 tertiary hospitals. Inquiry 2019;56:004695801989539.

10 Zhou H, Bai G, Gao J, et al. The development of indicator measure for monitoring the quality of patient-centered care in China's tertiary hospitals. PLoS One 2018;13:e0205489.

11 Wang X-Q, Wang X-T, Zheng J-J. How to end violence against doctors in China. The Lancet 2012;380:647-8.

12 An J. Which future for doctors in China? The Lancet 2013;382:936-7.

13 Yin S. Inside the doctor-patient relationship of China. Yale Global Health Review 2017.

14 Liu J, Mao Y. Patient satisfaction with rural medical services: a crosssectional survey in 11 Western provinces in China. Int $J$ Environ Res Public Health 2019;16:3968.

15 Dong W, Zhang Q, Yan C, et al. Residents' satisfaction with primary medical and health services in Western China. BMC Health Serv Res 2017; 17:298

16 Pan J, Liu D, Ali S. Patient dissatisfaction in China: what matters. Soc Sci Med 2015;143:145-53.

17 Sun J, Hu G, Ma J, et al. Consumer satisfaction with tertiary healthcare in China: findings from the 2015 China national patient survey. International Journal for Quality in Health Care 2017;123:213-21.

18 Cohen J. Statistical power analysis for the behavioral sciences. 2nd ed.. Hillsdale, NJ: Lawrence Erlbaum, 1988.

19 CMS. CAHPS Hospital survey, 2020. Available: https://hcahpsonline. org/en/survey-instruments/

20 Goldstein E, Farquhar M, Crofton C, et al. Measuring hospital care from the patients' perspective: an overview of the CAHPS Hospital survey development process. Health Serv Res 2005;40:1977-95.

21 LeBreton JM, Senter JL. Answers to 20 questions about interrater reliability and interrater agreement. Organizational Research Methods 2008;11:815-52.

22 Hox JJ, Moerbeek M, Van de Schoot R. Multilevel analysis: techniques and applications. Milton: Routledge, 2017.

23 CMS. Summary of HCAHPS survey results: October 2017 to September 2018 discharges. CMS, 2019. https://www.hcahpsonline. org/en/summary-analyses/previous-summary-analyses-documents/

24 Ong LML, de Haes JCJM, Hoos AM, et al. Doctor-patient communication: a review of the literature. Soc Sci Med 1995;40:903-18.

25 Boissy A, Windover AK, Bokar D, et al. Communication skills training for physicians improves patient satisfaction. J Gen Intern Med 2016;31:755-61.

26 Pantouvakis A, Bouranta N. Quality and price - impact on patient satisfaction. Int J Health Care Qual Assur 2014;27:684-96.

27 Clark AE. Job satisfaction and gender: why are women so happy at work? Labour Econ 1997;4:341-72.

28 Bai J. Docotors, please take a break. People's Daily 2014

29 Jin WW, Chen J. How busy are doctors? 70 patients in a half day. Zhejiang Online 2016.

30 Mather M, Mazar N, Gorlick MA, et al. Risk preferences and aging: the "certainty effect" in older adults' decision making. Psychol Aging 2012;27:801-16. 